\title{
IMPACTS OF A NEW SEASONAL WORK PROGRAM ON RURAL HOUSEHOLD INCOMES IN THE PACIFIC
}

\author{
John Gibson \\ University of Waikato \\ David McKensie \\ World Bank
}

\begin{abstract}
Seasonal work programs are increasingly advocated by international aid agencies as a way of enabling both developed and developing countries to benefit from migration. They are argued to provide workers with new skills and allow them to send remittances home, without the receiving country having to worry about long-term assimilation and the source country worrying about permanent loss of skills. However, formal evidence as to the development impact of seasonal worker programs is non-existent. This paper provides the first such evaluation, studying New Zealand's new Recognized Seasonal Employer (RSE) program which allows Pacific Island migrants to work in horticulture and viticulture in New Zealand for up to seven months per year. We use baseline and follow-up waves of surveys we are carrying out in Tonga to form difference-in-difference and propensity score matching estimates of short-term impacts on household income and consumption.
\end{abstract}

\section{Introduction}

A growing literature suggests that seasonal work programs (SWPs) are part of the new landscape of global agriculture that can be "win-win" for both developed and developing countries (GCIM, 2005; Pritchett, 2006). These SWPs appear to offer many of the benefits of migration - such as relieving labor shortages in developed countries and aiding development in developing countries - with few of the perceived costs such as permanent loss of talent in developing countries, and social stress, fiscal costs and irreversibility in developed countries.

Many countries have SWPs, with a 2003 ILO survey finding over 500 bilateral labor agreements.' Amongst the most widely studied of these, the Canadian Seasonal Agriculture Workers Program (SAWP) has been recruiting Caribbean workers for over forty years, and Mexican workers since 1974 (Brem, 2006). The SAWP lets 20,000 seasonal migrants work in Canadian agriculture for up to eight months per year. Other examples include 5,500 Moroccan mothers, who pick strawberries in Spain for a four month season, and 16,500 Bulgarians and Romanians who fill summer jobs in UK agriculture under the Seasonal Agricultural Workers Scheme. ${ }^{2}$ Perhaps the largest program involves 300,000 Polish guestworkers who can work for up to four months in German agriculture (Hess, 2006).

But robust evidence on the development impact of seasonal worker programs is non-existent. While claims are made about development impacts based on surveys of seasonal agricultural workers (Basok, 2000), these surveys lack baseline information from before the workers migrated and do not have control groups to see what would have happened to the supplying households in the absence of the seasonal migration. Similar methodological problems affect studies of internal seasonal migration, which typically rely on crosssectional data with no way of controlling for migrant selfselectivity (Haberfeld, et al. 1999). ${ }^{3}$

In this paper we report more robust impact estimates, for New Zealand's new Recognised Seasonal Employer (RSE) scheme. The RSE began in 2007 and aims to aid economic development in the Pacific Islands while easing labor shortages in New Zealand's horticulture and viticulture industries (Ramasamy et al, 2008). Under the RSE, up to 5000 workers from eligible Pacific Island countries are recruited to work in New Zealand for seven months per eleven month period and can return in future seasons if recruited again. The employer pays half of the return airfare from the worker's home country and provides stipulated minimum hours of work at hourly or piece rates typical of those received by local workers for equivalent work in the same period and region. Typical jobs for RSE workers are pruning trees and vines, picking applies, citrus and grapes, and picking and packing kiwifruit. Employers also arrange internal transportation and accommodation, provide training and equipment, and look after other aspects of pastoral care for their seasonal workers.

Our impact estimates are based on two waves of a panel survey that we designed specifically for evaluating the 
RSE. The first wave provides baseline data on households before workers left for the first season in New Zealand. In addition to households with RSE workers, the samples also includes households with individuals who applied to participate in the RSE but were not recruited (henceforth "RSE applicants"), and households where no individuals applied to the RSE (henceforth "non-applicants"). These control groups allow us to deal with two types of selection which might otherwise confound the inferences: first there is a selection process by firms, labor agents and community leaders which determines which applicants are recruited from work-ready pools formed in the source countries. Second, any self-selection process, whereby households decide whether to have members apply for the RSE work-ready pool, can be studied by comparing with the non-applicants.

Although our surveys are fielded in the two Pacific countries supplying most workers under the RSE Vanuatu and Tonga, the estimates reported here are restricted to Tonga. Over two-thirds of the Tongan RSE workers in our sample had returned home when the second wave of our survey was fielded (April-June, 2008) compared with only 20 percent of the Vanuatu workers. It is expensive to send money from New Zealand to the Pacific, with the transactions costs for popular money transfer operators like Western Union averaging at least 15 percent (Gibson, McKenzie and Rohorua, 2006). Consequently many RSE workers bring most of their earnings home in person, rather than sending them from in New Zealand. Therefore it is not possible to observe the full impact of RSE work on source household incomes until the worker has returned at the end of each season. The impacts for the Vanuatu households and for those Tongans who had not yet returned by the second wave of our survey will be captured by the third survey wave, which went into the field in October 2008.

We restrict attention to estimating impacts, in the form of average treatment effects on the treated (ATT), on household incomes and consumption. We do not yet attempt to estimate broader, community-level impacts on inequality or poverty. However prior analysis of the baseline data showed that Tongan workers coming through the RSE are poorer, more rural and less schooled than Tongans not participating in the RSE (Gibson et al., 2008). ${ }^{4}$ Hence any positive impacts on household income resulting from participation in the RSE are likely to be pro-poor.

\section{Data}

Our survey has near national coverage, covering the main island of Tongatapu, and two of the three outer island groups (Vava'u and 'Eua). Collectively these three islands contain 90 percent of the population and contributed 92 percent of the RSE workers in the first season. The sampled villages were based on lists of RSE workers and their villages obtained from the Tongan Labour Ministry. The town officer in each village provided directions to households with RSE workers and a random subset of these were interviewed. In each village we also used the town officers to identify households with RSE applicants who were part of the work-ready pool but who had not been recruited, and we additionally surveyed households where all members were non-applicants.

In total our baseline survey covered 448 households containing 2,335 individuals in 46 villages. The first follow-up survey re-interviewed 442 of these households. Of these, 181 had a RSE worker (114 where the worker had returned by the wave 2 survey), 116 had a member of the work-ready pool who had not been recruited, and 145 had only non-applicants. Table 1 summarizes baseline household-level characteristics for these four sample groups, along with two-sample $t$-tests for differences in means between the samples.

The households where RSE workers had already returned from their season in New Zealand had similar baseline welfare levels and largely similar baselines characteristics to those households whose workers were still completing their New Zealand contracts (as seen from columns (a) and (b)). The only differences are that those still in New Zealand came from households with slightly lower adult schooling levels and fewer chickens owned, and where adults had worked fewer days of hard physical labor at the time of the baseline survey. These differences should not affect the inferences derived from the two-thirds of RSE households with returned workers, although a more complete set of impact estimates will be possible once the wave 3 data are available.

In contrast, there are substantial differences between the RSE households and either applicant or non-applicant households. The average per capita incomes were over 250 pa'anga higher at baseline in applicant households and over 400 pa'anga higher in non-applicant households. ${ }^{5}$ The gap in per capita consumption was almost as large. These differences in per capita resources come from both a larger household size for RSE workers and also lower total incomes. Accounting for these preexisting differences will be important for valid estimates of the impact of RSE work on household incomes. The other main differences in characteristics are that RSE households have more previous experience of visiting New Zealand and also (amongst returnees) had spent more days per week engaged in hard physical labor at the time of the baseline survey.

\section{Estimation Model}

Let $Y_{1}$ and $Y_{0 i}$ be the income of a household in two counterfactual situations: the treatment $(T=1)$ of sending a household member to work in New Zealand under the RSE and non-treatment $\left(T_{t}=0\right)$. For a set of observable covariates, $X_{\text {, let }} P\left(X_{i}\right)$ be the propensity score, defined as: $P\left(X_{i}\right) \equiv \operatorname{Pr}\left(T_{i}=1 \mid X_{i}\right)$. The average treatment effect on the treated (ATT) can be estimated as:

$$
\begin{aligned}
A T T & \equiv E\left\{E\left[Y_{1}-Y_{0 i} \mid T_{i}=1, P\left(X_{i}\right)\right]\right\} \\
& =E\left\{E\left[Y_{1,} \mid T_{i}=1, P\left(X_{i}\right)\right]-E\left[Y_{0 i} \mid T_{i}=0, P\left(X_{i}\right)\right] \mid T_{i}=1\right\}
\end{aligned}
$$


which is interpreted as the expected gain in income for households with RSE workers compared with what their income would have been if not recruited. Conceptually the ATT requires a mean for the unobservable counterfactual, $E\left[Y_{0 i} \mid T_{i}=1\right]$ so for the observable quantities in equation (1) to identify the ATT relies on three key conditions introduced into the literature by Rosenbaum and Rubin (1983).

\section{First is "unconfoundedness" $\left(Y_{0 i}, Y_{1 i} \perp T_{i} \mid X_{i}\right)$, where $\perp$} denotes independence. According to this, potential outcomes are independent of treatment, conditional on the observable covariates, $X_{i}$. Given observable covariates, assignment to the treatment group is treated as random and any systematic differences in actual outcomes between treated and non-treated individuals with the same value of the covariates is attributed to the treatment. Second is "common support" where all treated households have a counterpart in the non-treatment group for each $X_{t}$ for which we seek to make a comparison.

This condition would appear to create a dimensionality problem when many covariates are matched on; for example, if $X$ contains $k$ covariates which are all

dichotomous the number of possible matches will be $2^{k}$. However the propensity score reduces the dimensionality of the matching problem because it is possible to match on $P\left(X_{1}\right)$ which is scalar, rather than on the vector of

observable variables $X_{1}$. This use of $P\left(X_{1}\right)$ is valid so long as the "balancing" property $\left(\operatorname{prob}\left(X_{i} \mid T_{i}=1, P\left(X_{i}\right)=p\right)=\operatorname{prob}\left(X_{i} \mid T_{i}=0, P\left(X_{i}\right)=p\right)\right)$

holds (Rosenbaum and Rubin, 1983). In other words, conditional on the propensity score, the means of the covariates should be identical across the treatment and control groups if the balancing property holds.

Since the propensity score is a continuous variable it is unlikely that there are two observations with exactly the same value of $P\left(X_{1}\right)$, so further refinement is needed to estimate equation (1). We use a "kernel matching" procedure, following Dehejia and Wahba (2002) where all treated households are matched with a weighted average of non-treated households, with weights inversely proportional to the gap between propensity scores of the treated and non-treated. The literature comparing propensity score matching with experimental benchmarks also notes that performance is better if treatment and control groups are located in the same labor markets, are administered the same questionnaire and if data is collected from both the pre- and post-treatment periods so a 'difference-in-differences' estimator can be used to control for unobserved differences between the treatment and control groups. All of these features are present in the survey that we use, with a common questionnaire obtaining baseline pre-migration and follow-up postmigration information and fielded in villages that supply both the treatment and control groups.

\section{Results}

An initial accounting of household income components, their change over time and the difference in these differences between households with RSE workers and those with applicants and with non-applicants is reported in Table 2. Seven components are considered: earnings in Tonga (based on individual reports for the previous week); net (i.e., also taking account of outbound) remittances of both money and goods from RSE workers (based on household reports on the previous six months), net remittances from other sources; the lump sum of repatriated earnings from returned RSE workers (based on a report by the returned worker); net returns from sales of fish, crops, livestock, tapa cloth and mats (based on household reports on an average month); the value of own-produced or own-captured food consumed by the household (based on household reports for the previous week); and other income from investments, pensions, rentals, etc. (based on household reports for the previous fortnight). Some of these income sources are either a lump sum or may come in only part of the year (e.g. remittances from RSE workers) so we do not annualize them since that may wrongly imply a more continuous, and higher, income from some sources. Instead we present them on a semi-annual basis, which was roughly the period since the baseline survey and also corresponds to the period for which RSE related income might accrue, given the seven month restriction on time spent in New Zealand. We will make estimates of annual income once data are available from wave 3 of the survey to add to the semi-annual income from wave 2 .

Almost half of income for RSE households and more than half for the other households is from subsistence production (Table 2, columns (a) to (d)). Repatriated RSE earnings and net remittances from RSE workers are the next most important income sources for RSE households, followed by earnings in Tonga. For non-RSE households, earnings in Tonga are the second most important income source. Across all sources, the per capita income of RSE households is approximately 300 pa'anga higher than for applicant and non-applicant households. However this is not a valid estimate of the treatment effect of participating in the RSE, since it does not take account of the baseline differences between the groups of households shown in Table 1.

To get closer to a valid treatment effect, we first consider the change in each income component, relative to the baseline level, which is reported in columns (e) to (h). The per capita (semi-annual) income for RSE households is 950 pa'anga higher than at baseline, with the biggest contribution from a rise in the value of subsistence production, ${ }^{7}$ followed by repatriated RSE earnings and net remittances from RSE workers. However, this change in income for RSE households is also not a valid estimate of the treatment effect of participating in the RSE, since it does not allow for the possibility that incomes might have increased from the baseline values irrespective of RSE participation. Indeed, columns (f) and (g) show that both applicant and non-applicant households also experienced income increases, mainly due to higher subsistence production but also due to higher earnings. 
Instead it is the difference in differences which take account of both pre-existing income differences between the groups of households and the growth in incomes which would have occurred anyway. These show that per capita income for RSE households increased by almost $600 \mathrm{pa}$ 'anga, relative to the increase recorded for applicant households and by over $700 \mathrm{pa}$ 'anga relative to the rise for non-applicant households. There is little evidence of crowding out, whereby some traditional sources of income fall once non-traditional (RSE) incomes become available, with the only statistically significant result being a slight fall in net remittances from non-RSE sources (only relative to the nonapplicants). The difference in differences is larger when compared with non-applicant households, suggesting some self-selection into the RSE applicant pool and making the applicant households the better counterfactual for what would have happened to the RSE households if they had not sent a worker to New Zealand.

However even the differences in differences between RSE and applicant households include some households in the comparison who may not be very similar. Propensity score matching is a way to deal with these non-comparable households, by restricting the estimation of treatment effects to just those households that obey the common support condition. In order to implement this, we use the levels and squares of the baseline variables listed in Table 1 as covariates, and estimate propensity scores for RSE households that range from 0.065 to 0.989 with a mean of 0.657 . The propensity scores for applicant households are much lower, ranging from 0.001 to 0.029 , with a mean of $0.333{ }^{8}{ }^{8}$ Figure 1 illustrates these in the form of kernel densities. It is apparent that there while some applicant households have characteristics like those of RSE households, many others do not. Therefore in all of the results that follow, estimation of the average treatment effect is restricted to the area of common support, where the two distributions overlap.

\section{Figure 1: Propensity Scores for RSE Households and Applicant Households}

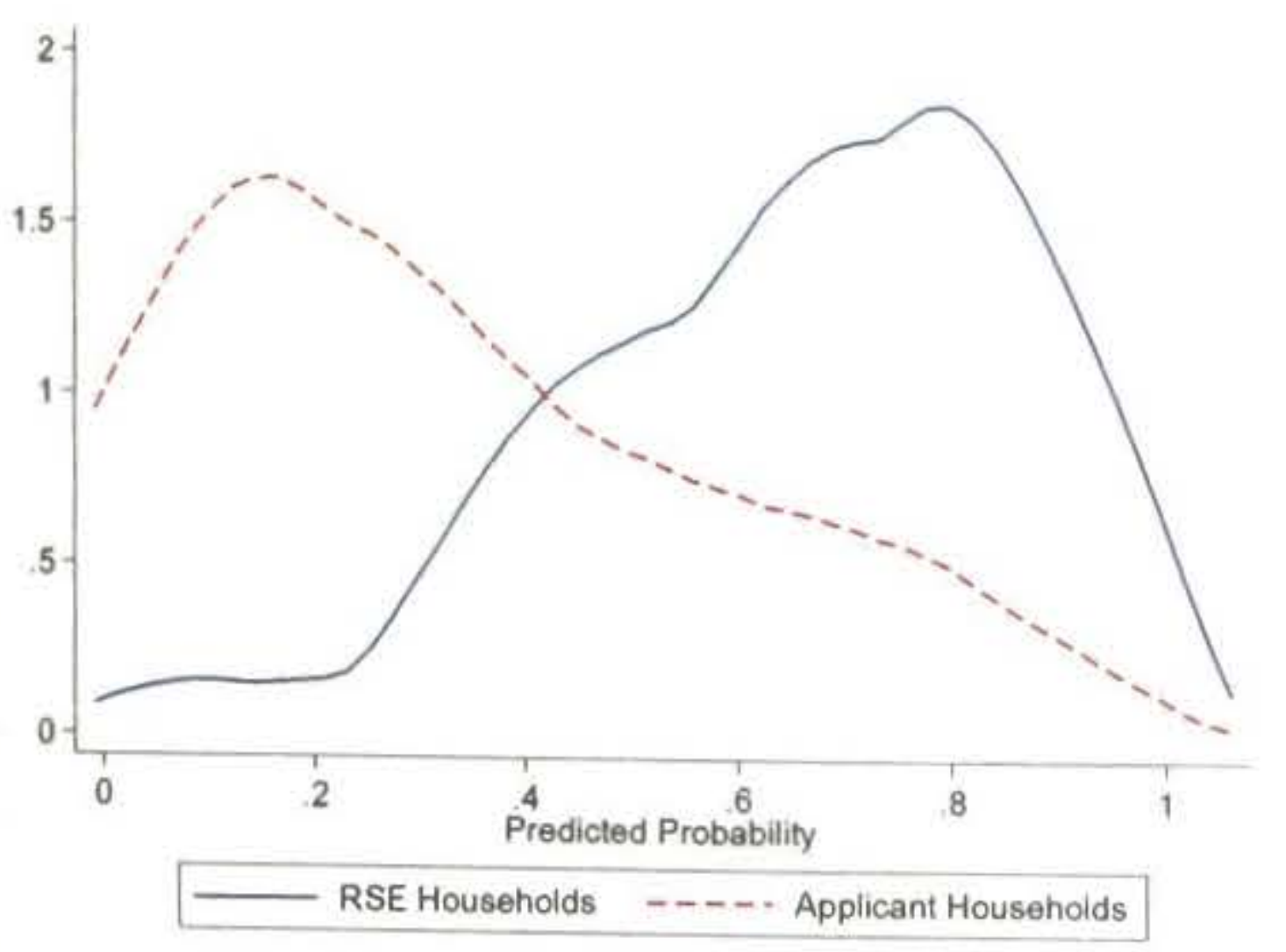

Table 3 reports estimates of the treatment effects for total per capita income and consumption, with either applicants or all non-RSE households used as the control group. We also show results for $\log$ income and consumption, which is less sensitive to outliers and for which the treatment effect is approximately a percentage change arising from having a household member seasonally work in New Zealand. These estimates suggest that per capita income for RSE households increased by an average of $520 \mathrm{pa}$ 'anga, matching against applicant households, or by $570 \mathrm{pa}$ 'anga matching against both applicant and non-applicant households.

These estimates are lower by about 60 pa'anga and 100 pa'anga, compared with the simple difference in difference estimates in Table 2 . That the treatment effects estimate falls by more when the non-applicants are included in the matching suggests that the applicants are the better counterfactual group for what would have happened to RSE households without any seasonal migration. This point is emphasized when considering the sample sizes that result from imposing the common support restriction; $84 \%(97 / 116)$ of the applicant sample are still used as a control group but only $69 \%(181 / 261)$ of the combined applicant and non-applicant sample are used.

The results in Table 3 for log per capita total income suggest that households with RSE workers have $66-76 \%$ higher incomes than either applicant households or all non-RSE households. ${ }^{9}$ Two caveats to this estimate are, first, that it is for a six-month period and only some of the income sources could be relied upon in the other six months of a year, given the seasonal nature of RSE employment, and second, the repatriated earnings of RSE workers are assumed to be pooled with other forms of household income, when in fact the worker may treat this as capital rather than as income and may not pool it with other members.

There is no apparent effect on per capita consumption from participation in the RSE. The treatment effects on the consumption variables are all statistically insignificant and close to zero. There was also no apparent impact on consumption in the difference in difference estimates in Table 2. It will take longer term monitoring to determine whether the higher income of RSE households ultimately translates into higher consumption.

\section{Conclusions}

Seasonal work programs are an increasingly discussed feature of global agriculture but there is no formal evidence evaluating their development impacts. In this study we find large short-term impacts on household incomes for Tongan participants in the new Recognized Seasonal Employer program which allows up to seven months work per year in New Zealand horticulture and viticulture. The per capita income of participating households is increased by over $500 \mathrm{pa}$ 'anga (equivalent to almost US\$300), although there is no apparent impact on consumption.

Our results also illustrate the importance of formal evaluation methods and suitable data. For example, the impacts would be understated if just a cross-sectional survey was used which ignored pre-existing differences 
between participants and other households. Conversely, impacts would be overstated by just looking at the change in income for participants without considering income changes amongst control groups. Impacts would also be overstated if households that are quite unlike are compared in a standard regression approach. More flexible methods of comparing households via propensity score matching are likely to give the most valid estimates of treatment effects and can best inform the ongoing debates about the role of seasonal work programs as development policy.

\section{Notes}

1. UN Secretary-General, International Migration and Development Report. May 16 2006, p. 82.

2. Rural Migration News July, 2007.<< http://migration.ucdavis.edu/rmn/more.php?id=12 $28 \_0 \_40>$

3. de Brauw and Harigaya (2007) are one example of internal seasonal migration being studied with panel data, but even in their example the first wave of the panel survey does not correspond to a premigration baseline.

4. In contrast, McKenzie et al. (2008) show that although RSE workers from Vanuatu coming to New Zealand are mostly male subsistence farmers with limited schooling, they are still from wealthier households and have better English literacy than the average ni-Vanuatu.

5. These income estimates are for a semi-annual period. In terms of international currencies, approximate exchange rates during the time of the survey are $1 \mathrm{NZD}=1.5 \mathrm{~Pa}$ 'anga and $1 \mathrm{USD}=1.9$ $\mathrm{Pa}$ anga.

6. If there are regions where the support of $X_{1}$ does not overlap for the treated and non-treated groups. matching can only be performed over the common support region.

7. The baseline survey was fielded at the end of the dry season in Tonga while the second wave survey was fielded 1-2 months after the wet season ended. In addition there is a considerable amount of feasting for church and family ceremonies in Tonga in May and June, which involve killing pigs. This consumption and rainfall seasonality and a domestic inflation rate of $12 \%$ at the time of the wave 2 survey may account for the rise in recorded value of subsistence production. The other seasonal pattern is that the main agricultural cash crop in Tonga is squash, which is harvested and exported at the end of the dry season, and so would not show up in the reference period for the wave 2 survey.
8. If applicant and non-applicant households are combined, the propensity scores range from 0.00 to 0.900 , with a mean of 0.214 .

9. These are calculated as $100 \times[\exp (0.508)-1]$ and $100 \times[\exp (0.569)-1]$.

\section{References}

Basok, T. (2000) "Migration of Mexican seasonal farm workers to Canada and development: Obstacles to productive investment" International Migration Review 34(1): 79-97.

Brem, M. (2006) "Migrant workers in Canada: A review of the Canadian Seasonal Agricultural Workers Program." Policy Brief North-South Institute. $<$ http://www.nsiins.ca/english/pdf/MigrantWorkers_Eng_Web.pdf $>$

de Brauw, A. and Tomoko H. (2007) "Seasonal migration and improving living standards in Vietnam" American Journal of Agricultural Economics 89(2): 430-447.

Dehejia, R. and Sadek W. (2002) "Propensity score matching methods for non-experimental causal studies" Review of Economics and Statistics 84(1): 151-161.

Gibson, J., McKenzie, D. and Rohorua, H. (2006) "How cost elastic are remittances? Evidence from Tongan migrants in New Zealand", Pacific Economic Bulletin, 21(1): 112-128.

Gibson, J., McKenzie, D. and Rohorua, H. (2008) "How pro-poor is the selection of seasonal migrant workers from Tonga under New Zealand's Recognized Seasonal Employer (RSE) program?" Pacific Economic Bulletin 23(3): 187-204.

Global Commission on International Migration (GCIM) (2005) Migration in an Interconnected World: New Directions for Action. www.gcim.org

Haberfeld, Y., Menaria, R., Sahoo, B. and Vyas, R. (1999) "Seasonal migration of rural labor in India" Population Research and Policy Review 18(5): 473-489.

Hess, S. (2006) "The demand for seasonal farm labor from Central- and Eastern European countries in German agriculture" Agricultural Engineering International: the CIGR Ejournal. 8(April) No. 28.

McKenzie, D., Martinez, P. G. and Winters, L. A. (2008) "Who is coming from Vanuatu to New Zealand under the new Recognised Seasonal Employer (RSE) program?" Pacific Economic Bulletin 23(3): 205-228. 
Pritchett, L. (2006) Let Their People Come. Breaking the Gridlock on Global Labor Mobility. Center for Global Development, Washington, D.C.

Ramasamy, S., Krishnan, V., Bedford, R. and Bedford, C. (2008) "The Recognised Seasonal Employer policy: seeking the elusive triple wins for development through international migration" Pacific Economic Bulletin 23(3): 171-186.

Rosenbaum, P. and Rubin, D. (1983) "The central role of the propensity score in observational studies for causal effects" Biometrika 70(1): 41-55.

\section{Acknowledgements}

Financial support from the World Bank is gratefully acknowledged. We thank the Government of the Kingdom of Tonga, the New Zealand Department of Labour, the survey interviewers and supervisors, and most especially the respondents. Helpful comments were received from seminar audiences at UC Davis. The views expressed here are those of the authors alone and do not necessarily reflect the opinions of the World Bank, the New Zealand Department of Labour, or the Government of Tonga.

\section{Authors}

John Gibson

\section{Professor}

Department of Economics

Waikato Management School

University of Waikato

Private Bag 3105

Hamilton 3240

JKGibson@waikato.ac.nz

Telephone: +64-7-838-4289

Fax: +64-7-838-4331

\section{David McKenzie}

Senior Economist

Development Research Group

Finance and Private Sector Development Unit

The World Bank

MSN MC3-307

1818 H Street

N.W.

Washington

DC 20433

USA

DMcKenzie@worldbank.org

\section{Appendix}

Table 1: Baseline Characteristics and Monetary Welfare Levels of Tongan Households with RSE Workers, Applicants and Non-Applicants

\begin{tabular}{|c|c|c|c|c|}
\hline & $\begin{array}{l}\text { Returned RSE } \\
\text { (a) }\end{array}$ & $\begin{array}{l}\text { RSE still in NZ } \\
\text { (b) }\end{array}$ & $\begin{array}{l}\text { Applicants } \\
\text { (c) }\end{array}$ & $\begin{array}{c}\text { Non-applicants } \\
\text { (d) }\end{array}$ \\
\hline Household size & 5.89 & 5.54 & $4.97 * * *$ & $4.74 * * *$ \\
\hline Adult ( $>14$ years) share of household & 0.65 & 0.59 & $0.72 * *$ & 0.68 \\
\hline Male share of adults & 0.55 & 0.56 & $0.51 * *$ & 0.52 \\
\hline Share of adults literate in English & 0.93 & 0.95 & 0.90 & 0.96 \\
\hline Share of adults with schooling beyond Grade 10 & 0.46 & 0.38 * & 0.49 & 0.47 \\
\hline Share of adults who previously visited New Zealand & 0.36 & 0.38 & $0.19 * * *$ & $0.17 * * *$ \\
\hline Average days of hard physical labor/person/week & 4.94 & $3.44 * * *$ & $4.11 \cdots$ & $4.12 * * *$ \\
\hline Number of pigs owned & 6.04 & 5.07 & 5.46 & 5.39 \\
\hline Number of chickens owned & 5.82 & 4.04 • & 4.91 & 5.35 \\
\hline Number of cattle owned & 0.54 & 0.36 & 0.47 & 0.42 \\
\hline Number of vehicles owned & 0.58 & 0.63 & 0.62 & 0.68 \\
\hline Per capita total household income & 844 & 803 & $1093 \cdots$ & $1247 * * *$ \\
\hline Per capita total household consumption & 805 & 877 & 993 ** & $1294 * *$ \\
\hline Sample size & 114 & 67 & 116 & 145 \\
\hline
\end{tabular}

Note: The "returned RSE" households are those where the worker had returned to Tonga by wave 2 of the survey while the "RSE still in NZ" are households where the worker was still at the time of wave 2 of the survey.

'The components of total household income and total household consumption are shown in Table 2 below

$* * *=$ significant at $0.01, * *=$ significant at $0.05, *=$ significant at 0.1 for comparison with the mean for the returned RSE households. 
Tabie 2. Houschold Ineome Components. Changes from Baseline and Difference in Differences for RSE. Applicant and Non-applicant Households in Tonga

\begin{tabular}{|c|c|c|c|c|c|c|c|c|c|c|c|}
\hline & \multicolumn{4}{|c|}{ Income Components (Pa'anga/capit: $/ 6$ months) } & \multicolumn{4}{|c|}{ Change in Income Components (from Baseline) } & \multicolumn{3}{|c|}{ Difference in Differences (is Control Groups) } \\
\hline & $\begin{array}{r}\text { RSE } \\
\text { (a) }\end{array}$ & $\begin{array}{l}\text { Applicants } \\
\text { (b) }\end{array}$ & $\begin{array}{l}\text { Non-applicants } \\
\text { (c) }\end{array}$ & $\begin{array}{l}\text { Non-RSF } \\
\text { (d) }\end{array}$ & $\begin{array}{r}\text { RSF } \\
\text { (e) } \\
\end{array}$ & $\begin{array}{r}\text { Applicants } \\
\text { (f) }\end{array}$ & $\begin{array}{r}\text { Nonapplicants } \\
\text { (g) } \\
\end{array}$ & $\begin{array}{r}\text { Non-RSE } \\
(h) \\
\end{array}$ & $\begin{array}{l}\text { Applicants } \\
\text { (c)-(f) }\end{array}$ & $\begin{array}{l}\text { Noti-applicants } \\
\text { (c)-(g) }\end{array}$ & $\begin{array}{l}\text { Non-RSE } \\
\text { (e)-(h) }\end{array}$ \\
\hline Earnings in Tonga & 163 & $360 * k$ & $346 * *$ & 353 \%** & -10 & 80 & 74 & 76 & -90 & -83 & -86 \\
\hline Net remittanees (from RSE:) & 355 & $1 * * 0$ & $0 * \cdots$ & 0 **. & 355 & 1 & 0 & 0 & 354 "** & $355 * 0 *$ & $354 * * *$ \\
\hline Net remittances (from other) & 50 & $85^{\circ *}$ & $98 * *$ & $92 * * *$ & .22 & 5 & 13 & 9 & -27 & $-34 *$ & $-31 \cdot$ \\
\hline Repatriated RSE earnings & 386 & $0 * * *$ & $0 \%$ & 0) $* t *$ & 386 & 0 & 0 & 0 & $386 * * *$ & 386 twn & $386 * * *$ \\
\hline Agricultural \& informal sales & 33 & $96 * * *$ & $101 * * *$ & $99 * * *$ & -215 & -164 & -252 & -213 & -51 & 36 & -2 \\
\hline Subsistence production & 809 & 918 & 921 & 920 & 457 & 448 & 385 & 413 & 8 & 71 & 43 \\
\hline Other income & 0 & 0 & 2 & 1 & 0 & -3 & 2 & 0 & 3 & -2 & 0 \\
\hline Total Household Income & 1795 & $1460 * *$ & $1469 \ldots$ & 1465 ** & 951 & 367 & 222 & 287 & $584 * * *$ & $728 * 0$. & $664 * * *$ \\
\hline Cash expenditure & 381 & 396 & 398 & 397 & -72 & -127 & -361 & -257 & 55 & 288 & 185 \\
\hline Total Household Consumption" & 1190 & 1315 & 1319 & 1317 & 384 & 321 & 25 & 157 & 63 & 360 & 228 \\
\hline Sample size & 114 & 116 & 145 & 261 & 114 & 116 & 145 & 261 & 230 & 259 & 375 \\
\hline
\end{tabular}

Note: The RSE households are only those where the wotker had retumed to Tonga by ware 2 of the survey (households where the worker was still in New Zealand are not included in Table 2.

The non-RSF, group is the sum of applicants and non-applicants.

"Total Household Constuniption is comprised of eash expenditure plus consumption of subsistence production.

$\cdots=$ significant at $0.01, \cdots$ significant at $0.05, \cdots$ - significant at 0.2 . In columus (b) to (d) significance is for comparison with column (a). In the difference in differences columns the significance is for coniparison with zero.

Table 3: Propensity Score Matching Estimates of Average Treatment Effects on Per Capita Monetary Welfare in Tonga from RSE Participation

\begin{tabular}{|c|c|c|c|c|c|c|}
\hline \multirow[b]{3}{*}{ Welfare indicator } & \multicolumn{6}{|c|}{ Set of households used as the control group } \\
\hline & \multicolumn{3}{|l|}{ Applicant households } & \multicolumn{3}{|c|}{ Applicant + non-applicant households } \\
\hline & $\begin{array}{l}\text { Average } \\
\text { treatment effect on } \\
\text { the treated (ATT) }\end{array}$ & $\begin{array}{l}\text { Bootstrap } \\
\text { standard } \\
\text { error }\end{array}$ & $\begin{array}{c}t \text {-statistic } \\
\text { on ATT }\end{array}$ & $\begin{array}{l}\text { Average } \\
\text { treatment effect on } \\
\text { the treated (ATT) }\end{array}$ & $\begin{array}{c}\text { Bootstrap } \\
\text { standard error }\end{array}$ & $\begin{array}{l}t \text {-statistic } \\
\text { on AT T }\end{array}$ \\
\hline Total household income per capita (PCY) & 522 & 153 & 3.41 & 566 & 124 & 4.56 \\
\hline $\ln (\mathrm{PCY})$ & 0.508 & 0.133 & 3.81 & 0.569 & 0.112 & 5.06 \\
\hline Total consumption per capita (PCCONS) & -1 & 161 & 0.01 & 49 & 99 & 0.50 \\
\hline $\ln (\mathrm{PCCONS})$ & 0.029 & 0.095 & 0.31 & 0.088 & 0.094 & 0.93 \\
\hline
\end{tabular}

Note: The ATT estimates only use observations that satisfy the common support assumption ( $\mathrm{n}=97$ in the control group of applicant households and $\mathrm{n}-18 \mathrm{I}$ when both applicant and non-applicant households are used) and come from a kemel matching procedure.

The standard errors are obtained via 100 bootstrap replications.

The covariates used for estimating the propensity scores are the levels and squares of the baseline characteristics listed in Table 1. 